Check for updates

Cite this: RSC Adv., 2017, 7, 34959

Received 28th May 2017

Accepted 5th July 2017

DOI: 10.1039/c7ra05979e

rsc.li/rsc-advances

\title{
Acid-promoted metal-free protodeboronation of arylboronic acids $\uparrow$
}

\author{
Guoqing Zhang, ${ }^{\text {b } Y a n g ~ L i}{ }^{\star a b}$ and Jianhui Liu (D) *ab
}

\begin{abstract}
A facile acid-promoted protodeboronation of arylboronic acids in the absence of metal catalysts or any other additives is described. This protodeboronation is general for a range of arylboronic acids with both electron-donating and electron-withdrawing groups in good to excellent yields under air atmosphere. Density functional theory mechanistic studies showed that the protodeboronation of arylboronic acids followed an intermolecular metathesis via a four-membered ring transition state. The effect of the substituent of arylboronic acids in protodeboronation is also theoretically studied.
\end{abstract}

\section{Introduction}

Arylboronic acids are versatile precursors in transition metalmediated or metal-free cross-coupling reactions to construct $\mathrm{C}-\mathrm{C}, \mathrm{C}-\mathrm{N}, \mathrm{C}-\mathrm{O}$, and other $\mathrm{C}-\mathrm{X}$ bonds. ${ }^{1}$ They are generally used in the Suzuki-Miyaura cross-coupling reaction ${ }^{2}$ and transition metal-catalyzed self-coupling reactions ${ }^{3}$ to form (un)symmetrical biaryl compounds. However, the protodeboronation of arylboronic acids is sometimes a side reaction to compete with Suzuki coupling, due to the strong nucleophilic character of the arylboronic acids. Compared to the dimerization of arylboronic acid, less attention has been paid to the protodeboronation of arylboronic acids. The deliberate removal of the $-\mathrm{B}(\mathrm{OH})_{2}$ that acted as a blocking/directing group in several examples gives the protodeboronation increased value. For example, Aggarwal applied the protodeboronation of allylic boronic esters to afforded trisubstituted alkenes. ${ }^{4}$ The protodeboronation was also applied by Aggarwal in the asymmetric synthesis to afforded tertiary alkyl stereogenic centers, ${ }^{5}$ tertiary alcohols and arylethanes. ${ }^{6}$ Carreño reported the significance of the protodeboronation in the regioselective Friedel-Crafts alkylation in which $-\mathrm{B}(\mathrm{OH})_{2}$ played a temporary regiocontroller. ${ }^{7}$ Therefore, the protodeboronation has great application potential in the organic synthesis and increasing interest has been given to this research field.

Although several methods have been reported, mainly including the use of base and/or metal catalysts $\left(\mathrm{Pd} / \mathrm{K}_{2} \mathrm{CO}_{3},{ }^{8} \mathrm{Cu} /\right.$ isopropamide, $\left.{ }^{9} \mathrm{Ag} / \mathrm{TEA}^{\mathbf{1 0}}\right)$, acid-mediated protodeboronation has seldom been described, ${ }^{\mathbf{1 1}}$ since the acid-mediated

${ }^{a}$ State Key Laboratory of Fine Chemicals, Dalian University of Technology, Dalian 116024, P. R. China.E-mail: zgqdut8023@mail.dlut.edu.cn; chyangli@dlut.edu.cn ${ }^{b}$ School of Petroleum and Chemical Engineering, Dalian University of Technology, Panjin Campus, Panjin, Liaoning Province, 124221, P. R. China

$\dagger$ Electronic supplementary information (ESI) available. See DOI: 10.1039/c7ra05979e protodeboronation would be retarded when the arylboronic acids were substituted with electron-withdrawing groups. ${ }^{12}$

The study about the protodeboronation kinetics by LloydJones showed that the protodeboronation rates were $\mathrm{pH}$ dependent. ${ }^{13}$ Acid-mediated protodeboronation of allylic boronic esters was reported several years ago. ${ }^{4}$ Recently, a mild reaction condition for the protodeboronation of arylboronic acids, which used $\mathrm{AcOH}$ in 1,4-dioxane, was described by Cheon, ${ }^{\mathbf{1 4}}$ but only electron-donating groups showed better results. He also reported the metal-free protodeboronation of ortho- and para-phenol boronic acids in wet DMSO under thermal conditions. ${ }^{15}$

\section{Results and discussion}

In an effort to prepare thiophene 2 in our recent studies of dyesensitized solar cells, we found that the standard Knoevenagel condensation of 5-formyl-2-thiopheneboronic acid (1) with cyanoacetic acid did not give the expected thiophene 2 , but the protodeboronation product 3 was afforded instead (Scheme 1). This finding inspired us to investigate the protodeboronation of other arylboronic acids.

In our attempted Knoevenagel condensation mentioned above, the protodeboroation product was afforded. Since a good yield $(71 \%)$ was obtained, we decided to expand this conversion to other substrates. The screen of the reaction conditions was

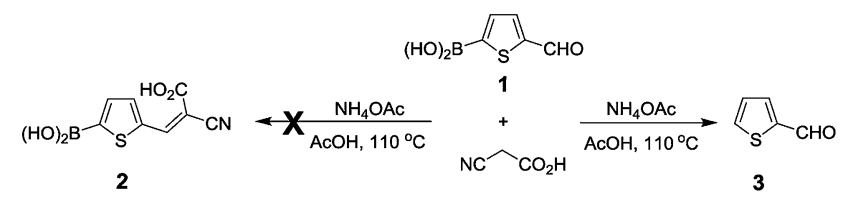

Scheme 1 The unexpected protodeboronation rather than condensation. 


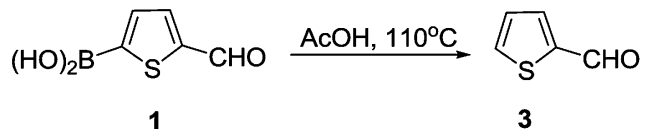

Scheme 2 Protodeboronation of 5-formyl-2-thiopheneboronic acid.

still required before we started our study. In the original Knoevenagel, $\mathrm{NH}_{4} \mathrm{OAc}$ was used as a weakly basic catalyst to capture the reactive hydrogen. In order to check whether $\mathrm{NH}_{4} \mathrm{OAc}$ played a role in the protodeboronation, we conducted a control experiment where 2-formylthiophene (3) was still obtained in a yield of $72 \%$ without using $\mathrm{NH}_{4} \mathrm{OAc}$ (Scheme 2). This proved that $\mathrm{AcOH}$ alone could promote this reaction and therefore the following studies was performed in $\mathrm{AcOH}$ in the absence of $\mathrm{NH}_{4} \mathrm{OAc}$. Although the protodeboronation of organoboronic acid by acids was known, but only with formic acid and several inorganic acids. ${ }^{16}$ No systematic studies were found in the literatures using $\mathrm{AcOH}$. In addition, the early study was focused mainly on the kinetics of the protodeboronation. ${ }^{16}$ This inspired us to explore a mild and an efficient acid-promoted protodeboronation universale for various arylboronic acid.

The optimization of reaction conditions for the acidmediated protodeboronation was performed first, and 4hydroxyphenylboronic acid (4a) was chosen as a substrate. The examination of the solvent indicated that acetic acid is the best acidic medium for the protodeboronation process (yield of $70 \%$ ), followed by $\mathrm{HCOOH}$ with a lower yield of $45 \%$, mixed solvents of $\mathrm{AcOH} / \mathrm{H}_{2} \mathrm{O}$ and $\mathrm{HCl} / \mathrm{H}_{2} \mathrm{O}$ with further decreased yields of no more than $30 \%$ ( $23 \%$ and $26 \%$, respectively), and $\mathrm{CF}_{3} \mathrm{COOH}$ being totally inactive (Table 1 , entries $1-5$ ). The influence of the temperature was also investigated. As shown in the same table, the yield of the phenol increased steadily with increasing temperature (Table 1, entries 6-9). Finally, $130{ }^{\circ} \mathrm{C}$ was determined as the best temperature for the reaction.

Under these optimized conditions, different arylboronic acids were used as substrates to confirm the usefulness of the

Table 1 Influence of solvent and temperature ${ }^{a}$

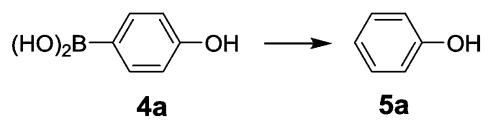

\begin{tabular}{llll}
\hline Entry & Solvent & $T\left({ }^{\circ} \mathrm{C}\right)$ & Yield $^{b}(\%)$ \\
\hline 1 & $\mathrm{AcOH}$ & 110 & 70 \\
2 & $\mathrm{HCOOH}$ & 110 & 45 \\
3 & $\mathrm{AcOH} / \mathrm{H}_{2} \mathrm{O}$ & 110 & 23 \\
4 & $\mathrm{HCl} / \mathrm{H}_{2} \mathrm{O}$ & 110 & 26 \\
5 & $\mathrm{CF}_{3} \mathrm{COOH}$ & 110 & 0 \\
6 & $\mathrm{AcOH}$ & 25 & 8 \\
7 & $\mathrm{AcOH}$ & 50 & 58 \\
8 & $\mathrm{AcOH}$ & 80 & 63 \\
9 & $\mathrm{AcOH}$ & 130 & 81
\end{tabular}

${ }^{a}$ Reaction conditions: arylboronic acids $(0.5 \mathrm{mmol})$, AcOH $(10 \mathrm{~mL})$, under air, 1 h. ${ }^{b}$ Isolated yields. acid-promoted protodeboronation, except for several cases where the conversions were conducted at $110{ }^{\circ} \mathrm{C}$ due to the lower boiling point of the corresponding protodeboronation products (Table 2, entries $\mathbf{7 - 1 1}$, for $\mathbf{5 g}, \mathbf{5 h}, \mathbf{5 j}$ ). The results are summarized in Table 2. Electron-donating groups exhibited a better effect on both rate and yield than electron-withdrawing groups. The protodeboronation of arylboronic acids with electron-donating groups, such as $-\mathrm{OH},-\mathrm{OCH}_{3},-\mathrm{Ph},-\mathrm{CH}_{3}$, were completed in 1-4 h with yields between $78-92 \%$ (Table 2, entries 1-7). The position of the groups on the phenyl ring had no obvious effect on the reaction (Table 2, entries 2 vs. 3, 8 vs. 9, 10 vs. 11 and 15 vs. 12). In addition, both the arylboronic acid $4 d$ with the strong steric hindrance of two $2-\mathrm{CH}_{3} \mathrm{O}$ and the polycyclic arylboronic acid $\mathbf{4 f}$ could afford excellent yields of $88 \%$ and $92 \%$ (Table 2, entries 4 and 6). Conversely, as expected, electron-withdrawing groups (such as $-\mathrm{Br},-\mathrm{Cl},-\mathrm{NO}_{2},-\mathrm{COCH}_{3}$, $-\mathrm{CHO},-\mathrm{COOH},-\mathrm{COOCH}_{3}$ ), decreased the yield of the protodeboronation, furnishing yields of $52-71 \%$, except for $4-\mathrm{Cl}$ $(85 \%), 3-\mathrm{COCH}_{3}(80 \%)$ and $4-\mathrm{CHO}(84 \%)$, in a reaction time of 5-20 h (Table 2, entries 8-19). Although no difference was observed in the yields between weaker electron-withdrawing groups such as $-\mathrm{Br}$ and $-\mathrm{Cl}(55-85 \%)$ and stronger electron-

Table 2 Protodeboronation of arylboronic acids in acetic acid ${ }^{a}$

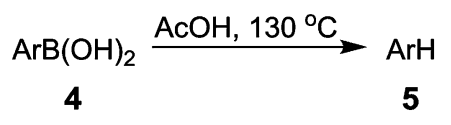

\begin{tabular}{|c|c|c|c|c|c|}
\hline Entry & $\mathrm{Ar}$ & Compound & Time(h) & Product & Yield $^{b}(\%)$ \\
\hline 1 & $4-\mathrm{HO}-\mathrm{C}_{6} \mathrm{H}_{4}$ & $4 a$ & 1 & $5 \mathbf{a}$ & 81 \\
\hline 2 & $4-\mathrm{CH}_{3} \mathrm{O}-\mathrm{C}_{6} \mathrm{H}_{4}$ & $4 b$ & 4 & $5 \mathbf{b}$ & 84 \\
\hline 3 & $3-\mathrm{CH}_{3} \mathrm{O}-\mathrm{C}_{6} \mathrm{H}_{4}$ & $4 c$ & 4 & $5 \mathbf{b}$ & 85 \\
\hline 4 & $2,6-\left(\mathrm{CH}_{3} \mathrm{O}\right)_{2}-\mathrm{C}_{6} \mathrm{H}_{3}$ & $4 d$ & 3 & $5 d$ & 88 \\
\hline 5 & $4-\mathrm{Ph}-\mathrm{C}_{6} \mathrm{H}_{4}$ & $4 e$ & 3 & $5 e$ & 83 \\
\hline 6 & 9-Anthryl & 4f & 3 & $5 f$ & 92 \\
\hline 7 & $4-\mathrm{CH}_{3}-\mathrm{C}_{6} \mathrm{H}_{4}$ & $4 \mathrm{~g}$ & 3 & $5 g$ & $78^{c}$ \\
\hline 8 & $4-\mathrm{Br}-\mathrm{C}_{6} \mathrm{H}_{4}$ & $4 h$ & 5 & $5 h$ & $55^{c}$ \\
\hline 9 & $3-\mathrm{Br}-\mathrm{C}_{6} \mathrm{H}_{4}$ & $4 \mathbf{i}$ & 5 & $5 \mathbf{h}$ & $70^{c}$ \\
\hline 10 & $4-\mathrm{Cl}-\mathrm{C}_{6} \mathrm{H}_{4}$ & $4 j$ & 5 & $5 \mathbf{j}$ & $85^{c}$ \\
\hline 11 & $3-\mathrm{Cl}-\mathrm{C}_{6} \mathrm{H}_{4}$ & $4 \mathbf{k}$ & 5 & $5 \mathbf{j}$ & $71^{c}$ \\
\hline 12 & $3-\mathrm{NO}_{2}-\mathrm{C}_{6} \mathrm{H}_{4}$ & 41 & 10 & 51 & 62 \\
\hline 13 & $3-\mathrm{CH}_{3} \mathrm{CO}-\mathrm{C}_{6} \mathrm{H}_{4}$ & $4 \mathrm{~m}$ & 8 & $5 \mathrm{~m}$ & 80 \\
\hline 14 & $3-\mathrm{CHO}-\mathrm{C}_{6} \mathrm{H}_{4}$ & $4 n$ & 8 & $5 n$ & 52 \\
\hline 15 & $4-\mathrm{NO}_{2}-\mathrm{C}_{6} \mathrm{H}_{4}$ & 40 & 10 & 51 & 65 \\
\hline 16 & $4-\mathrm{CH}_{3} \mathrm{CO}-\mathrm{C}_{6} \mathrm{H}_{4}$ & $4 p$ & 16 & $5 \mathrm{~m}$ & 69 \\
\hline 17 & $4-\mathrm{CHO}-\mathrm{C}_{6} \mathrm{H}_{4}$ & $4 q$ & 8 & $5 n$ & 84 \\
\hline 18 & $4-\mathrm{COOH}-\mathrm{C}_{6} \mathrm{H}_{4}$ & $4 r$ & 8 & $5 r$ & 63 \\
\hline 19 & $4-\mathrm{CH}_{3} \mathrm{COO}-\mathrm{C}_{6} \mathrm{H}_{4}$ & $4 s$ & 20 & $5 s$ & 69 \\
\hline 20 & $2-\mathrm{CH}_{3} \mathrm{COO}-\mathrm{C}_{6} \mathrm{H}_{4}$ & $4 t$ & 2 & $5 r$ & $66^{d}$ \\
\hline 21 & & $4 \mathbf{u}$ & 2 & $5 \mathbf{u}$ & 96 \\
\hline 22 & UAC & 1 & 2 & 3 & 84 \\
\hline
\end{tabular}




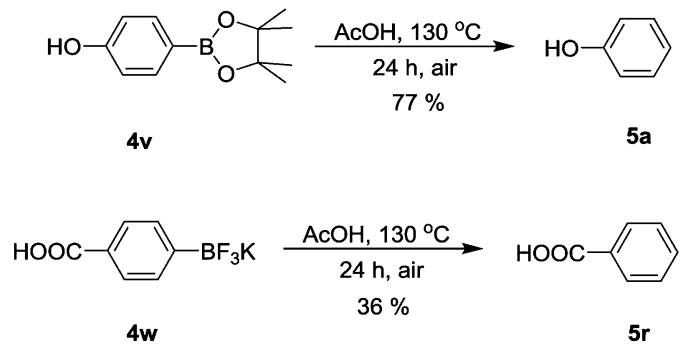

Scheme 3 Protodeboronation of 4-hydroxyphenylboronic acid pinacol ester and potassium 4-carboxyphenyltrifluoroborate.

withdrawing groups such as $-\mathrm{NO}_{2},-\mathrm{COCH}_{3},-\mathrm{CHO},-\mathrm{COOH}$ and $-\mathrm{COOCH}_{3}(52-84 \%)$, the reaction rates clearly differed. Protodeboronation of arylboronic acids with strong electronwithdrawing groups required longer reaction times of $8-20 \mathrm{~h}$ (Table 2, entries 12-19). This proved that electron deficiency of the $\mathrm{C}-\mathrm{B}$ bond did not favor the reaction. Extraordinarily, arylboronic acid substituted with $-\mathrm{COOCH}_{3}$ on the ortho-position did not give the protodeboronated methyl benzoate, but was directly hydrolyzed to benzoic acid $\mathbf{5 r}$ in just $2 \mathrm{~h}$ (Table 2 , entry 20). Heterocyclic boronic acids ( $\mathbf{4 u}$ and $\mathbf{1}$ ) could also easily provide the protodeboronation product in excellent yields of $96 \%$ and $84 \%$ under these conditions (Table 2, entries 21 and 22). In general, the results above demonstrate the universality of this reaction.

To further explore the scope of the substrates, the protodeboronation of other surrogates such as 4-hydroxyphenylboronic acid pinacol ester (4v) and potassium 4carboxyphenyltrifluoroborate (4w) were studied. The protodeboronation of $\mathbf{4 v}$ and $\mathbf{4 w}$ still proceeded although longer reaction time was required $(24 \mathrm{~h})$ (Scheme 3$) .4 v$ gave the protodeboronation product in a yield of $77 \%$, while $\mathbf{4 w}$ affored a lower yield of $36 \%$. The arylboronic acid pinacol ester and potassium aryltrifluoroborate display enhanced chemical stability compared with arylboronic acids. ${ }^{17}$ The slower protodeboronation rates may be due to the decreased Lewis acidity of the boron atom from arylboronic acid pinacol ester and potassium aryltrifluoroborate, which is consistent with Cheon's studies. ${ }^{14,15}$

Aryl iodides, important building blocks in forming $\mathrm{C}-\mathrm{C}$ and $\mathrm{C}-\mathrm{X}(\mathrm{X}=$ heteroatom $)$ bond, are widely used in organic synthesis. ${ }^{18}$ As we know, the regioselective iodination of arenes is usually difficult. ${ }^{19}$ While the 4 -iodoanisole (8) was successfully formed in a total yield of $61 \%$ through the AcOH-promoted protodeboronation in which the $-\mathrm{B}(\mathrm{OH})_{2}$ acted as a directing group (Scheme 4).

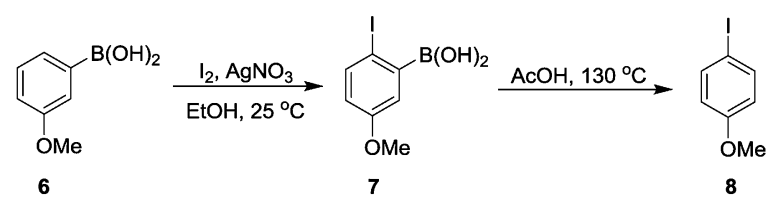

Scheme 4 The protodeboronation of arylboronic acid was applied in the synthesis of 4-iodoanisole.

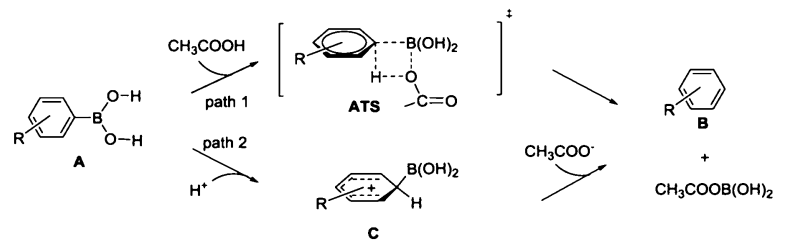

Scheme 5 The proposed mechanism for protodeboronation of arylboronic acids.

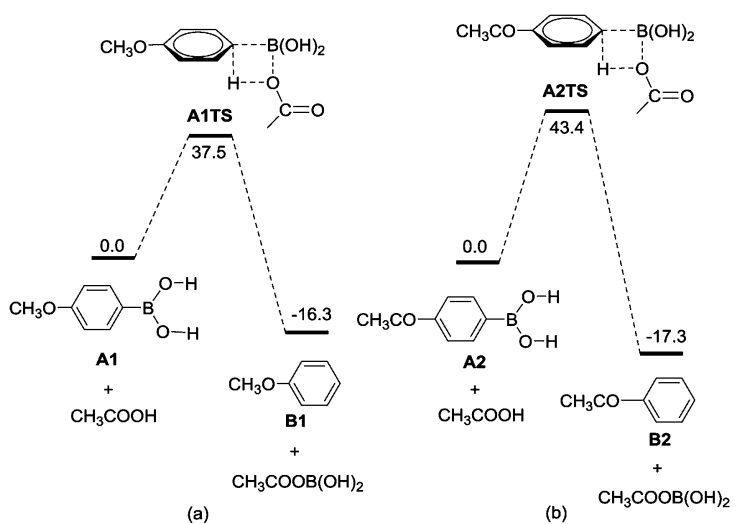

Fig. 1 The energy profiles calculated for the protodeboronation of A1 and $\mathrm{A} 2$.

For the protodeboronation of arylboronic acids, as shown in Scheme 5, there are two scenarios to address the aryl-H bond formation: (1) arylboronic acids A react with $\mathrm{AcOH}$ to form aryl complex B via a four-membered ring transition state ATS (path 1); (2) arylboronic acids $\mathrm{A}$ can be attack by $\mathrm{H}^{+}$reagent to form complex $\mathbf{C}$, and then $\mathrm{OAc}^{-}$attack the $-\mathrm{B}(\mathrm{OH})_{2}$ motif through $\mathrm{B}-\mathrm{C}$ bond cleavage and form aryl complex $\mathbf{B}$ (path 2). With the help of DFT calculations, the energy profiles of the protodeboronation of arylboronic acids are calculated in Fig. 1. Fig. 1 shows that the arylboronic acids react directly with $\mathrm{AcOH}$ to form aryl-H bond via an intermolecular metathesis process. We failed to locate the complex $\mathbf{C}$ in path 2 , which means the complex $\mathbf{C}$ is unlikely to be involved as the stable intermediate in the protodeboronation.

In order to understand the effect of the substituent of arylboronic acids in protodeboronation, we compared the reaction profiles starting from the arylboronic acids A1 with electrondonating group (entry 2 in Table 2) and arylboronic acids A2 with electron-withdrawing group (entry 16 in Table 2). From the energy profiles shown in Fig. 1, we can clearly see that protodeboronation of $\mathbf{A 1}$ (Fig. 1a, with an energy barrier of $37.5 \mathrm{kcal}$ $\mathrm{mol}^{-1}$ ) has lower energy barrier than that of $\mathbf{A 2}$ (Fig. 1b, with an energy barrier of $43.4 \mathrm{kcal} \mathrm{mol}^{-1}$ ). Electronically, the boronbonded carbon in $\mathbf{A 1}$ is electron-rich when compared with that in $\mathbf{A 2}$ because of the electron property of substituent of arylboronic acids. The natural bond orbital (NBO) analysis shows that the natural atomic charges of the boron-bonded carbon are calculated to be -0.468 in $\mathbf{A 1}$ and -0.409 in A2, respectively, suggesting that the $\mathrm{AcOH}$ reagent favors attack of 
the boron-bonded carbon in A1 over that in A2. These results are consistent with the experimental observation that arylboronic acids with electron-donating group have high yield with short reaction time than that with electron-withdrawing group.

\section{Conclusions}

In conclusion, we have achieved an acid-mediated protodeboronation from a wide variety of arylboronic acid substrates. Compared to other methods reported before, it is a greener process in that no any metal catalysts and additives are needed. The only use of acetic acid is highly practical. In addition, the electron-withdrawing groups can also be tolerated in the protodeboronation. This method could be an attractive complement to the case in which substituents of the arylboronic acids are susceptible to alkaline medium. An intermolecular metathesis reaction mechanism was developed based on DFT calculations. Additionally, the NBO analysis provided information on the effect of the substituent of arylboronic acids.

\section{Acknowledgements}

The financial support of this study was from the State Key Laboratory of Fine Chemicals (Panjin) (Grant No. JH2014009) project and the Fundamental Research Funds for the Central Universities. Professor Yang Li thanks the Scientific Research Foundation of Dalian University of Technology (Grant No. DUT16RC(3)037) and Supercomputing Center of Dalian University of Technology for providing access to the supercomputer.

\section{Notes and references}

1 (a) A. Suzuki, Angew. Chem., Int. Ed., 2011, 50, 6722; (b) C. Zhu and J. R. Falck, Adv. Synth. Catal., 2014, 356, 2395; (c) C. Zhu, G. Li, D. H. Ess, J. R. Falck and L. Kürti, J. Am. Chem. Soc., 2012, 134, 18253; (d) C. Zhu, R. Wang and J. R. Falck, Org. Lett., 2012, 14, 3494.

2 (a) P. Basnet, S. Thapa, D. A. Dickie and R. Giri, Chem. Commun., 2016, 52, 11072; (b) G. Xu, W. Fu, G. Liu, C. H. Senanayake and W. Tang, J. Am. Chem. Soc., 2014, 136, 570; (c) N. Miyaura, T. Yanagi and A. Suzuki, Synth. Commun., 1981, 11, 513.
3 (a) C. A. Contreras-Celedón, J. A. Rincón-Medina, D. Mendoza-Rayo and L. Chacón-García, Appl. Organomet. Chem., 2015, 29, 439; (b) H. Mizuno, H. Sakurai, T. Amaya and T. Hirao, Chem. Commun., 2006, 5042; (c) C. GonzálezArellano, A. Corma, M. Iglesias and F. Sánchez, Chem. Commun., 2005, 1990; (d) A. S. Demir, Ö. Reis and M. Emrullahoglu, J. Org. Chem., 2003, 68, 10130.

4 M. J. Hesse, C. P. Butts, C. L. Willis and V. K. Aggarwal, Angew. Chem., Int. Ed., 2012, 51, 12444.

5 S. Nave, R. P. Sonawane, T. G. Elford and V. K. Aggarwal, J. Am. Chem. Soc., 2010, 132, 17096.

6 C. G. Watson and V. K. Aggarwal, Org. Lett., 2013, 15, 1346.

7 M. Veguillas, M. Ribagorda and M. C. Carreno, Org. Lett., 2011, 13, 656.

8 R. Y. Lai, C. L. Chen and S. T. Liu, J. Chin. Chem. Soc., 2006, 53, 979.

9 C. Liu, X. Li, Y. Wu and J. Qiu, RSC Adv., 2014, 4, 54307.

10 C. Liu, X. Li and Y. Wu, RSC Adv., 2015, 5, 15354.

11 (a) H. G. Kuivila and K. V. Nahabedian, J. Am. Chem. Soc., 1961, 83, 2164; (b) B. Floris and G. Illuminati, J. Organomet. Chem., 1978, 150, 101; (c) R. D. Brown, A. S. Buchanan and A. A. Humffray, Aust. J. Chem., 1965, 18, 1521.

12 (a) J. Lozada, Z. Liu and D. M. Perrin, J. Org. Chem., 2014, 79, 5365; (b) K. V. Nahabedian and H. G. Kuivila, J. Am. Chem. Soc., 1961, 83, 2167.

13 P. A. Cox, A. G. Leach, A. D. Campbell and G. C. Lloyd-Jones, J. Am. Chem. Soc., 2016, 138, 9145.

14 S. J. Ahn, C. Y. Lee, N. K. Kim and C. H. Cheon, J. Org. Chem., 2014, 79, 7277.

15 C. Y. Lee, S. J. Ahn and C. H. Cheon, J. Org. Chem., 2013, 78, 12154.

16 H. G. Kuivila and K. V. Nahabedian, J. Am. Chem. Soc., 1961, 83, 2159.

17 (a) M. Schnürch, M. Holzweber, M. D. Mihovilovic and P. Stanetty, Green Chem., 2007, 9, 139; (b) D. Kuik, J. A. McCubbin and G. K. Tranmer, Synthesis, 2017, 49, 2555; (c) G. A. Molander and L. N. Cavalcanti, J. Org. Chem., 2011, 76, 623.

18 T. S. Mei, D. H. Wang and J. Q. Yu, Org. Lett., 2010, 12, 3140. 19 (a) R. M. Al-Zoubi and D. G. Hall, Org. Lett., 2010, 12, 2480; (b) C. Y. Zhou, J. Li, S. Peddibhotla and D. Romo, Org. Lett., 2010, 12, 2104. 